\title{
A randomised, double blind, placebo controlled trial of botulinum toxin in the treatment of spastic foot in hemiparetic patients
}

\author{
P Burbaud, L Wiart, J L Dubos, E Gaujard, X Debelleix, P A Joseph, J M Mazaux, \\ B Bioulac, M Barat, A Lagueny
}

\begin{abstract}
Objective-To confirm the apparent effectiveness of botulinum toxin (BTX) in hemiparetic patients with ankle plantar flexor and foot invertor spasticity. Methods-Twenty three hemiparetic patients with spasticity of the ankle plantar flexors and foot invertors were included in a randomised double blind, placebo controlled study with BTX. Patients were examined on days $0,30,90$, and 120 and received one injection of BTX and one of placebo in a random order at day 0 and day 90.

Results-Patients reported a clear subjective improvement in foot spasticity after BTX $(P=0.0014)$ but not after placebo. Significant changes were noted in Ashworth scale values for ankle extensors $(P<0.0001)$ and invertors $(P=0.0002)$, and for active ankle dorsiflexion $(P=$ $0 \cdot 0001)$. Gait velocity was slightly but not significantly $(P=0.0731)$ improved after BTX injections. The severity of spasticity did not modify treatment efficacy, but BTX was less effective in patients with longer duration of spasticity $(P=0 \cdot 0081)$. Conclusion-The efficacy of BTX injections in the treatment of spastic foot suggests that BTX may be particularly useful during the first year after a stroke.
\end{abstract}

(F Neurol Neurosurg Psychiatry 1996;61:265-269)

Department of

Neurophysiology

P Burbaud

B Bioulac

Department of

Neurology

A Lagueny

J L Dubos

Department of

Physical Medicine and

Rehabilitation, Hôpital

Haut-Lévèque, Avenue

Magellan, 33604

Pessac, France

L Wiart

E Gaujard

$X$ Debelleix

P A Joseph

J M Mazaux

M Barat

Correspondence to:

Dr Pierre Burbaud, Service d'Explorations

Fonctionnelles du Système

Nerveux, Hôpital Haut-

Lévèque, Avenue Magellan

33604 Pessac, France.

Received 7 November 1995

and in final revised form

and in final revisec

Accepted for publication

Accepted for p
Keywords: foot spasticity; botulinum toxin; double blind trial

Spasticity of the ankle plantar flexor and foot invertors is a major problem in the management of hemiparetic patients and may seriously impair walking rehabilitation. None of the usual treatments is totally satisfying in this focal form of spasticity. Oral medications are often only slightly effective, and their side effects limit their usefulness. ${ }^{12}$ Intrathecal infusion of baclofen reduces spasticity but is not without risk for ambulation. ${ }^{3}$ Neural blockade with phenol or alcohol is often painful and may result in prolonged paraesthe$\mathrm{sia}^{4}$ although some authors have reported good functional results with long lasting effects and few complications. ${ }^{5}$ Orthopaedic surgery remains palliative and neurosurgical procedures may be shunned at the early stage because of their invasive and definitive nature. ${ }^{4}$ Meanwhile, pronounced improvement of spasticity with few side effects has been reported after selective neurotomy. ${ }^{6}$

Botulinum toxin (BTX) may represent a useful alternative approach. For roughly 10 years, it has been successfully used in the treatment of focal dystonia and various neurological disorders. ${ }^{78}$ This has recently led to the suggestion that it might help in the treatment of spasticity. ${ }^{910}$ Its temporary effect makes BTX particularly interesting in treating patients who are likely to recover ambulation in the first few months after a stroke. Previous open trial studies have reported substantial amelioration in the muscle tone of spastic patients, both in the upper ${ }^{11-13}$ and lower limbs. ${ }^{1013-19}$ To confirm the apparent effectiveness of BTX, double blind, placebo controlled studies have been called for, ${ }^{20}{ }^{21}$ and this we set out to do in a population of adult hemiparetic patients with ankle plantar flexor and foot invertor spasticity.

\section{Methods}

All patients in this study were referred for management of spasticity of the foot and came from several rehabilitation centres in southwest France. They gave their informed consent to participate in this double blind study. Inclusion criteria were the presence, for at least three months, of moderate to severe spasticity of the ankle plantar flexors and foot invertors and a lack of response to conventional physical and medical treatment. No change in antispastic treatment was allowed during the course of the study. Exclusion criteria included fixed joint posture, pregnancy, and neuromuscular diseases. All patients continued with active physiotherapy after the injections.

The patients were examined at day 0,30 , 90 , and 120 and received one injection of botulinum toxin and one of placebo in a random order, one at day 0 and the other at day 90. Treatment efficacy was reported subjectively by patients (on a scale of 0 to 3 ) and objectively by clinical rating scales. The modified Ashworth scale ${ }^{22}$ and the Fugl-Meyer scale $^{23}$ for the inferior limb were applied by an experienced physiotherapist (JLD) and data were recorded by a neurologist (PB). In this manner, the first did not know the scores he had given the same patient previously. The second performed the injection but did not clinically evaluate the patients. For evaluation of active dorsiflexion, a global score (from 0 to 6 ) was calculated from the three items of the FuglMeyer scale which directly concern active ankle dorsiflexion in the supine, sitting, and 
Table 1 Epidemiological and clinical characteristics of patients at inclusion

\begin{tabular}{|c|c|c|}
\hline $\begin{array}{l}\text { Clinical } \\
\text { variables }\end{array}$ & $\begin{array}{l}B T X \text { first } \\
(n=10) \\
\text { mean }(S D)\end{array}$ & $\begin{array}{l}\text { Placebo first } \\
(n=13) \\
\text { mean (SD) }\end{array}$ \\
\hline $\begin{array}{l}\text { Age (y) } \\
\text { Spasticity duration (months) } \\
\text { Video score } \\
\text { Fugl-Meyer score } \\
\text { Gait velocity (cm/s) } \\
\text { Ashworth ankle extensors } \\
\text { Ashworth ankle invertors } \\
\text { Active ankle dorsiflexion }\end{array}$ & $\begin{array}{r}50 \cdot 7(11) \\
23 \cdot 2(36) \\
3 \cdot 0(0 \cdot 5) \\
23 \cdot 7(4 \cdot 5) \\
28 \cdot 5(12) \\
3 \cdot 9(0 \cdot 6) \\
3 \cdot 2(1 \cdot 0) \\
2 \cdot 4(1 \cdot 5)\end{array}$ & $\begin{array}{r}53.9(16) \\
23.8(33) \\
3 \cdot 1(0.7) \\
23.4(5.4) \\
25 \cdot 4(15) \\
3.7(0.7) \\
2.8(0.9) \\
2.0(1.5)\end{array}$ \\
\hline
\end{tabular}

standing positions (from 0 to 2 for each item). At each visit, patients were videotaped during walking and their gait velocity was calculated over an arbitrary constant distance $(10 \mathrm{~m}) .^{24}$ At the completion of the study, the videotapes for the four sessions were assessed by the same observer (JLD) who did not know whether BTX or placebo had been given. This clinical gait assessment (score from 0 to 4 ) took into account the severity of equinovarus deformity, instability of gait stance, and the existence of knee extension.

Botulinum toxin A (Dysport, Speywood) was diluted with saline to a concentration of 200 Dysport units $/ \mathrm{ml}$ (total volume $5 \mathrm{ml}$ ) and

Figure 1 Influence of the first injection (Placebo or $B T X)$ on clinical score evolution. Vel = gait velocity $(\mathrm{cm} / \mathrm{s}) ; F M=$ Fugl-Meyer score; Vid $=$ video score $(\times 10)$; Ext $=$ ankle extensors Ashworth score; Inv = ankle invertors Ashworth score; Act $=$ active ankle dorsiflexion; $B=$

botulinum. $D=$ day. The arrow indicates when $B T X$ was injected. The number of patients in each group is $n=13$ for the first $\left(D_{0}=\right.$ placebo) and $n=10$ for the second ( $D_{0}=B$ toxin).
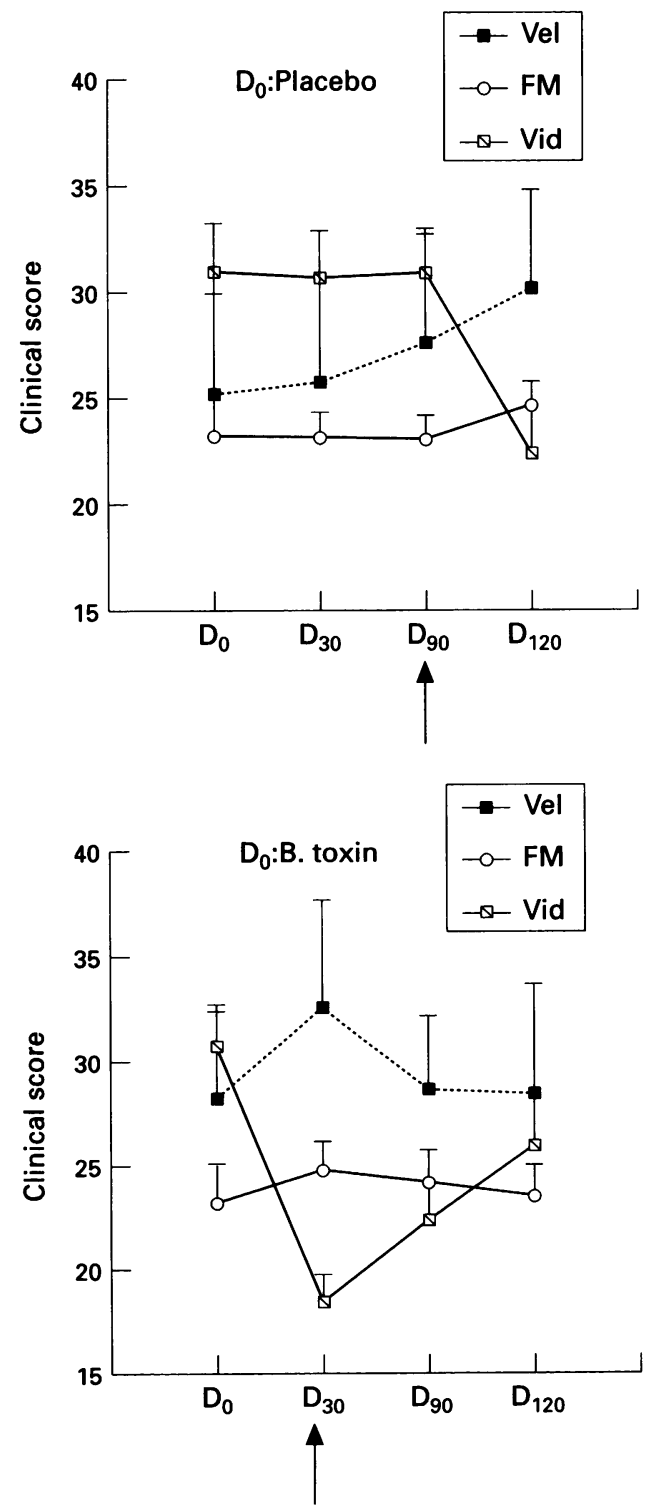

injected through a 26 gauge injectrode under electromyographic guidance (Dantec, 13R19) in two to six points per muscle. In this study, a constant total dose of 1000 Dysport units (25 ng) was distributed among the various muscles involved according to their contribution to spasticity judged clinically and confirmed by EMG. The choice of 1000 units was based on previous open trials in which a lower dose (500 units) proved to be ineffective in certain patients, and on economic considerationsthat is, a posology of BTX with an acceptable benefit:cost ratio. Placebo (saline $0.9 \%, 5 \mathrm{ml}$ ) was injected under exactly the same conditions. The range of BTX dosage for individual muscles ( $n=$ number of patients) was as follows: triceps surae (500-1000 units, $n=23$ ), soleus (200-400 units, $n=5)$, tibialis posterior (200-350 units, $n=5)$, and flexor digitorum longus $(150-300$ units, $n=2)$. The delay between injections (three months) was based on previous studies in spastic patients. ${ }^{21}$

The various clinical scales were compared one month after each injection (BTX and placebo) by a non-parametric Wilcoxon rank paired test. Initially, data from the two groups of patients who received placebo or BTX at
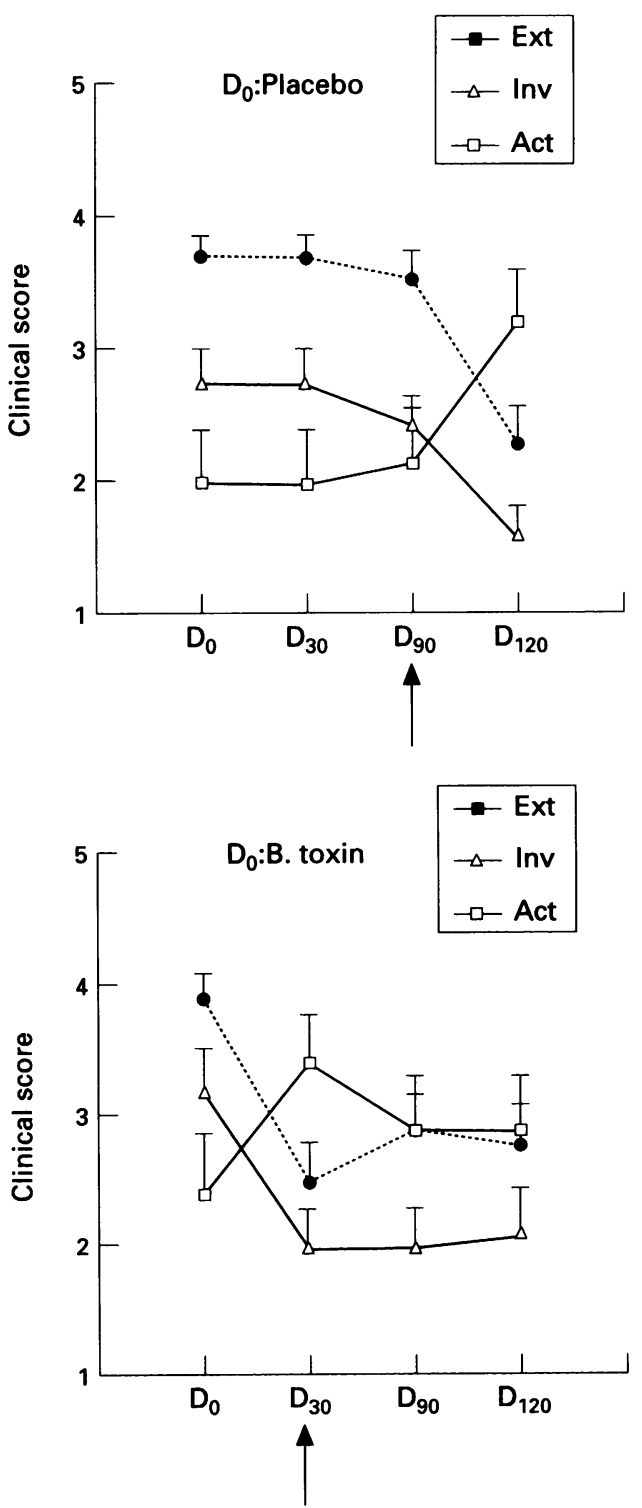
Table 2 Evolution of clinical rating scales before and one month after BTX injections

\begin{tabular}{lcc}
\hline $\begin{array}{l}\text { Clinical } \\
\text { rating scales }\end{array}$ & $\begin{array}{l}\text { Before BTX } \\
(n=23) \\
\text { mean }(S D)\end{array}$ & $\begin{array}{l}\text { After BTX } \\
(n=23) \\
\text { mean }(S D)\end{array}$ \\
\hline Video score & $3 \cdot 1(0 \cdot 6)$ & $2 \cdot 0(0 \cdot 6)^{\star \star \star}$ \\
Gait velocity (cm/s) & $25 \cdot 1(17 \cdot 1)$ & $29 \cdot 4(16 \cdot 4)$ \\
Fugl-Meyer score & $23 \cdot 5(4 \cdot 9)$ & $25 \cdot 0(4 \cdot 7)^{\star}$ \\
Ashworth ankle extensors & $3 \cdot 7(0 \cdot 7)$ & $2 \cdot 4(0 \cdot 9)^{\star \star \star}$ \\
Ashworth ankle invertors & $2 \cdot 8(0 \cdot 9)$ & $1 \cdot 8(0 \cdot 9)^{\star \star \star}$ \\
Active ankle dorsiflexion & $2 \cdot 2(1 \cdot 5)$ & $3 \cdot 3(1 \cdot 4)^{\star \star \star}$ \\
\hline${ }^{\star}<<0 \cdot 05 ;{ }^{\star \star \star P}<0.001$. & &
\end{tabular}

day 0 were studied separately, then data from both groups were pooled to evaluate the clinical benefits obtained from BTX injection in the whole population. Differences between groups of patients were compared by the MannWhitney $U$ test.

\section{Results}

Twenty three chronic hemiparetic patients (16 male and seven female) with a mean age of 51.3 (SD 13.9) (range 14-72) years were enrolled in this study. Data from seven patients who dropped out after one or two sessions were not taken into account. Neurological diagnoses included 19 cases of stroke (14 by ischaemia and five by haemorrhage) and four cases of traumatic hemiparesis. Eleven patients presented right hemiparesis

Figure 2 Active dorsiflexion in different positions before and after BTX injections. Clinical scores are quoted from the Fugl-Meyer rating scale. Data are pooled for the 23 patients.
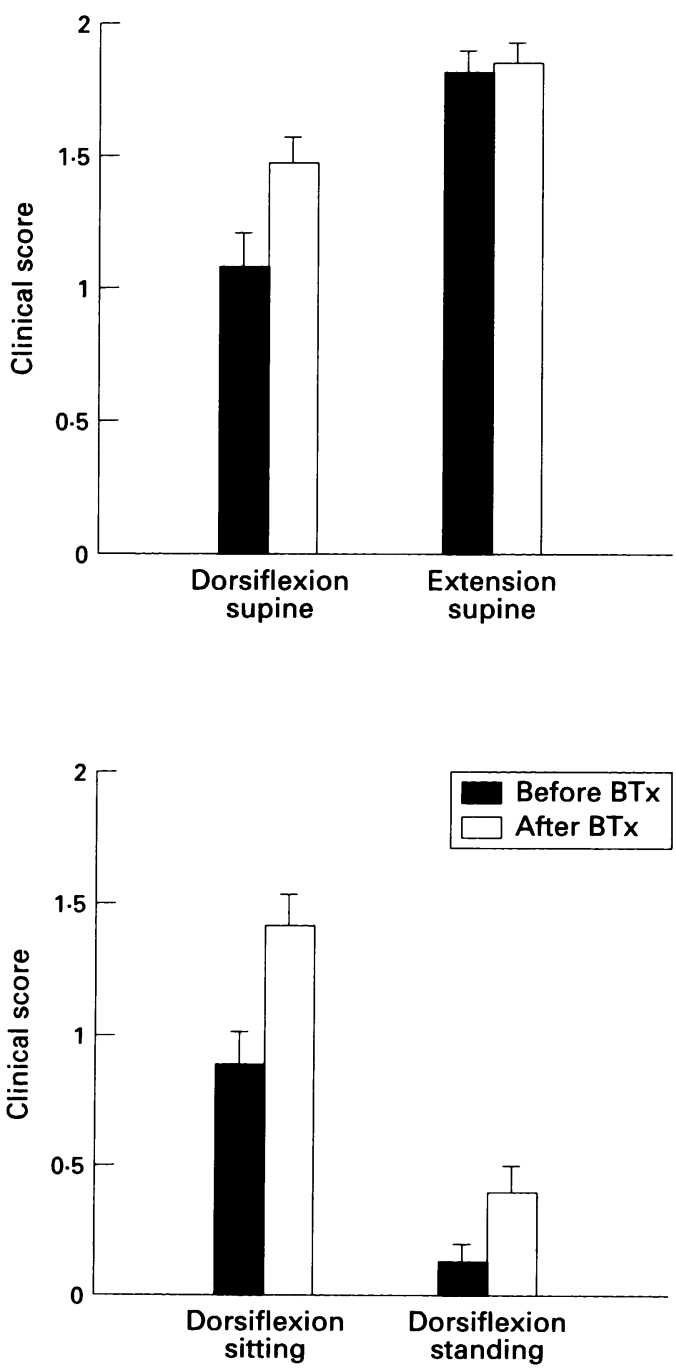

and 12 left hemiparesis. Significant hypoaesthesia was noted in 15 and aphasia in 10 (including nine moderate forms and one severe aphasia). The mean duration of spasticity was 23.5 (SD 33.8) (range 3.5 to 120 ) months, but was less than one year in 15 patients. Thirteen patients received the placebo and 10 patients BTX as their first injection (performed at day 0). Except for a different female:male ratio $(2: 8$ in the first $v$ $5: 8$ in the second) both groups of patients did not differ in any of their epidemiological or clinical characteristics (table 1). In particular, there was no difference in duration of spasticity or spasticity severity evaluated according to different rating scales.

Only three of the 23 patients reported no improvement after treatment with BTX. Among the 20 others, the subjective score increased by at least two points in 13. Four patients reported an improvement of one point after placebo. There was a clear difference ( $P$ $=0.0014)$ in patients' subjective scores between BTX (1.5 (SD 0.8)) and placebo (0.2 $(S D 0 \cdot 4)$ ). Figure 1 shows the responses of patients who received BTX $(n=10)$ or placebo $(n=13)$ as the first injection. When placebo was given at day 0 , a slight but nonsignificant evolution in gait velocity and Ashworth ankle scores was noted between day 0 and day 90 sessions. Except for gait velocity, all clinical scores were statistically different between day 90 and day 120 ( $\mathrm{P}<0.01)$. When BTX was given at day 0 , a difference was found between day 0 and day 90 (but not with day 120) for the video $(P=0.0103)$ and the Fugl-Meyer score $(P=0.0067)$. Although an increase in gait velocity was noticed at day 30 the difference was not statistically significant due to the large SD. Most importantly, a difference was found between day 0 and day 30 for the three clinical ankle scores: Ashworth extensors, Ashworth invertors, and active dorsiflexion $(P<0.0001)$. The difference was still significant between day 0 and day 90 or day 120 for both extensor $(P=0.0067$, $P=0.0058)$ and invertor $(P=0.0087, P=$ $0.0114)$ Ashworth scores but not between day 0 and day $90(P=0.2964)$ or day $120(P=$ $0 \cdot 2616)$ for active dorsiflexion.

Table 2 shows pooled clinical data from the 23 patients before and one month after BTX injections. The video score was significantly higher $(P=0.0002)$ after BTX injection but not after placebo. Gait velocity improved (velocity change $>7 \mathrm{~cm} / \mathrm{s}$ ) in only eight of 22 patients after BTX injection. Results from one patient were not used in data analysis as she was not able to walk independently at inclusion. The difference in gait velocity before and after BTX injection did not quite reach significance $(P=0.0731)$. A slight but significant improvement in the Fugl-Meyer score $(P=$ 0.0028 ) was found after BTX injection. Also, after treatment with BTX, two patients who previously could not walk independently were able to walk alone with an ordinary stick, two were able to exchange their tripod stick for an ordinary stick, and two others no longer needed sticks. The Ashworth scale values for 
Table 3 Influence of severity and duration of spasticity on BTX efficacy

\begin{tabular}{lll}
\hline Clinical improvement & $\begin{array}{l}\text { Ashworth ankle extensors } \\
\text { mean }(S D)\end{array}$ & $\begin{array}{l}\text { Subjective score } \\
\text { mean }(S D)\end{array}$ \\
\hline Ankle Ashworth score $<7(\mathrm{n}=11)$ & $1 \cdot 3(0 \cdot 6)$ & $1 \cdot 5(0 \cdot 8)$ \\
Ankle Ashworth score >7 $7(\mathrm{n}=12)$ & $1 \cdot 4(0 \cdot 9)$ & $1.4(0 \cdot 8)$ \\
Spasticity < 1 y $(\mathrm{n}=15)$ & $1 \cdot 7(0 \cdot 6)^{\star}$ & $1.9(0 \cdot 6)^{\star}$ \\
Spasticity > $1 \mathrm{y}(\mathrm{n}=8)$ & $0 \cdot 7(0 \cdot 7)$ & $0 \cdot 7(0 \cdot 70)$ \\
\hline
\end{tabular}

Clinical improvement corresponds to the difference in clinical scores studied before and one month after BTX injection. The ankle Ashworth score is the sum of ankle extensor and ankle invertor Ashworth scores at inclusion in the study.

$\star \mathrm{P}<0.05$. placebo were significant in the diverse clinical scales employed, for both passive and active movements. The more obvious improvement during passive testing compared with that of active movements is probably due to antagonist muscle paresis. Indeed, active ankle dorsiflexion will be facilitated by BTX injection of the plantarflexors if the ankle dorsiflexor muscles (tibialis anterior) are not overly paretic. On the other hand, a decrease in foot spasticity may modify the balance of segmental tonic influences and improve volitional control of antagonist muscles. It may also facilitate motor command by compensatory central programmes which are likely to play a part in walking rehabilitation. This is why it seems necessary to propose a comprehensive rehabilitation programme along with BTX injections. $^{25}$

Although gait stance was reported by patients as improved, the effect of BTX injections on walking velocity did not reach significance. Many factors may interfere with walking velocity in hemiparetic patients, explaining the variability. Indeed, some patients who initially walked with the help of some devices (stick, semirigid ankle orthesis) no longer needed them after BTX treatment. They may, however, walk more slowly through caution or apprehension. The lack of improvement in gait velocity could also reflect a detrimental effect of the toxin, which might produce too much weakness in plantar flexion. Against this hypothesis is the fact that, at the doses used in the present study, we found neither differences before and after BTX injections in the active ankle extension score of the Fugl-Meyer scale nor in clinical testing of foot extension strength. The mechanism by which BTX may improve foot spasticity during walking was not investigated in the present study, based on clinical evaluation. Previous authors using three dimensional gait analysis have reported that foot placement and stability, stride length, and foot force point of action were improved by BTX injections in hemiparetic patients. ${ }^{1819}$

This double blind crossover study was designed to compare the benefits from BTX or placebo treatment in each patient, not to provide an accurate evaluation of the duration of treatment efficacy. Duration might be more adequately studied by comparing groups of BTX and placebo treated patients at various times after injection. Despite this limitation, it should be noted that when BTX was given at day 0 , the baseline ankle Ashworth scores remained low at day 90 and day 120 suggesting that benefits from BTX could persist for three months or longer. This was confirmed by us in a parallel open trial (unpublished data). Variable duration of BTX effect from six weeks ${ }^{18}$ to six months ${ }^{913}$ has been reported in the treatment of lower limb spasticity. This point could be clarified by further studies at fixed doses for specific muscles.

The optimal dose to use in the treatment of spastic foot needs to be established. The doses used in previous studies ranged from 500 to 2000 units. $^{21}$ In a preliminary open study in 
four patients we found that 500 units was ineffective in decreasing spasticity in the triceps surae. In subsequent studies, we used a standard dose limited to 1000 units per injection for treating spastic drop foot, in an attempt to maintain the benefit:cost ratio as acceptable as possible. In a parallel open trial study, we have found that higher doses (1500 units) provide longer duration of efficacy without any significant side effects, as previously reported. ${ }^{1218}$ However, it should be borne in mind that the use of high doses in long term treatment, besides raising cost, may induce the formation of antibodies, as reported in patients chronically treated with BTX for spasmodic torticolis. ${ }^{26-28}$

The only factor which seemed to influence the efficacy of BTX injections in this study was the duration of spasticity. Patients having had this disability longer improved less after treatment, suggesting that the degree of benefit may correlate with the duration of spasticity. This might be explained by alterations in mechanical properties of muscle due to gradual structural muscular changes. ${ }^{19}{ }^{29}$ Also, tendon retractions or joint modifications may not have been entirely absent in patients with longer term spasticity even though patients with fixed joint position were excluded from this study. Our data are at variance with those of Dunne et $a l^{13}$ who found no relation between improvement and duration of spasticity. The reason for the discrepancy between these studies is not clear but may be related to differences in toxin doses or in range of spasticity duration.

One of the main problems in treating spasticity with BTX is its cost:benefit ratio. ${ }^{20}$ The clinical benefit of BTX injection was about four months in our study for a relatively high treatment cost. The fact that longer term spasticity seems to benefit less from BTX injection (at the doses used in this study) and that joint retractions may interfere with its efficacy, suggests that this treatment may be of greater benefit shortly after a stroke, when it is also likely to facilitate physiotherapy. There is indeed a particular challenge to treat patients before the occurrence of fixed retractions, during the period of recoverable abilities. Later on, when evolution in motor capacities and spasticity are unlikely, other more invasive techniques such as selective neurotomy, ${ }^{6}$ tendinotomy, or other surgical treatments may be useful. ${ }^{4}$ The advantage of BTX injections is that they are non-invasive and have adjustable clinical effects. Further studies are needed to compare the cost:benefit ratio of BTX versus other treatments of focal lower limb spasticity, although different techniques may well be complementary at various times after a stroke.

We thank Dr C Borde, P Carlier, E Douce, P Dabadie, J P Gouverneur, $H$ Petit, and $S$ Pujol for referring their patients. $M$ Geneste and $M$ Oliver are thanked for their help in managing the patients. We are also grateful to the Speywood Company for their support.

1 Young RR, Delwaide PJ. Drug therapy: spasticity (first of two parts). N Engl f Med 1981;304:28-33.

2 Young RR, Delwaide PJ. Drug therapy: spasticity (second of two parts). N Engl F Med 1981;304:96-99.

3 Penn RD, Savoy SM, Corcos D, et al. Intrathecal baclofen for severe spinal spasticity. $N$ Eng $f$ Med 1989;320: for sever

4 Herz DA, Looman JE, Tiberio A, Ketterling K, Kreitsch RK, Colwill JC, Grin OD. The management of paralytic spasticity. Neurosurgery 1990;26:300-6.

5 Petrillo CR, Knoplech S. Phenol block of the tibial nerve: a long term follow up study. Int Disabil Studies 1988;10:97-100.

6 Privat JM, Privat C. Sectorial posterior rhizotomy for the treatment of spasticity in adults. In: Neurosurgery for spasticity. A multidisciplinary approach. New York: Springer Verlag, 1990:141-3.

7 American Academy of Neurology. Assessment: the clinical usefulness of botulinum toxin- $A$ in treating neurological disorders. Neurology 1990;40:1332-6.

8 Clinical use of botulinum toxin A. National Institute of Health consensus development statement. Arch Neurol 1991;48:1294-7.

9 Das TK, Park DM. Botulinum toxin in treating spasticity. Br f Clin Pract 1989;43:401-2.

10 Snow BJ, Tsui JL, Bhatt MH, Varelas M, Hashimoto SA, Clane DB. Treatment of spasticity with botulinum toxin: a double blind study. Ann Neurol 1990;28:512-5.

11 Mémin B, Pollak P, Hommel M, Perret J. Traitement de la spasticité par la toxine botulique. Rev Neurol 1992;148: $212-4$.

12 Hesse S, Friedrich H, Domasch C, Mauritz KH. Botulinum toxin therapy of upper-limb spasticity: preliminary results. fournal of Rehabilitation Science 1992;5:98-101.

13 Dunne JW, Heye N, Dunne SL. Treatment of chronic limb spasticity with botulinum toxin A. $\mathcal{F}$ Neurol Neurosurg spasticity with botulinum

14 Dengler R, Neyer U, Wolfarth K, Bettig U, Janzic HH. Local botulinum toxin in the treatment of spastic drop foot. $\mathcal{F}$ Neurol 1992;239:375-8.

15 Konstanzer A, Ceballos-Bauman AO, Dressnandt J, Conrad B. Locale injektionsbehandlung mit Botulinumtoxin A bei schwerer arm-und bainspastic. Nervenartzt 1993;64:517-23.

16 Borg-Stein J, Pine ZM, Miller JR, Brin MF. Botulinum toxin for the treatment of spasticity in multiple sclerosis. Am $\mathcal{F}$ Phys Med Rehabil 1993;72:364-8.

17 Koman LA, Mooney JF, Smith B, Goodman A, Mulvaney T. Management of cerebral palsy with botulinum toxinA: preliminary investigation. $f$ Pediatr Orthop 1993;13: A: prelimir.

18 Hesse S, Lücke D, Malezic $M$, Bertelt C, Friedrich $H$, Gregoric M, Mauritz KH. Botulinum toxin treatment of lower limb extensor spasticity in chronic hemiparetic lower limb extensor spasticity in chronic hemiparetic
patients. F Neurol Neurosurg Psychiatry 1994;57:1321-4.

19 Cosgrove AP, Corry IS, Graham HK. Botulinum toxin in the management of the lower limb in cerebral palsy. Dev Med Child Neurol 1994;35:379-85.

20 Benecke $R$. Botulinum toxin for spasms and spasticity in the lower extremities. In: Jankovic J, Halett $M$, eds. Therapy with botulinum toxin. 1st ed. New York: Marcel Dekker, 1994:523-34.

21 Tsui JKC, O'Brian CF. Clinical trials for spasticity. In: Jankovic J, Halett $M$, eds. Therapy with botulinum toxin. 1st ed. New York: Marcel Dekker, 1994:557-65.

22 Bohannon RW, Smith MB. Interaliability of a modified Ashworth scale of muscle spasticity. Physical Therapy 1987;67:206-7.

23 Fugl-Meyer AR, Jösköl L, Leyman I, Olsson S, Speglind S. The post-stroke hemiplegic patients. Method for evaluation of physical performance. Scand F Rehabil Med 1975; 7:13-3

24 Wade TT. Measure of motor impairment. In: Measurement in neurological rehabilitation. Oxford: Oxford University Press, 1992:154-7.

25 Hesse S, Berteldt C, Mauritz KH. Botulinum-toxin A for treatment of lower limb spasticity during a comprehensive rehabilitation program. Mov Disord 1995;10:391.

26 Poewe W, Wiessel J. Experience with botulinum toxin in cervical dystonia. In: Jankovic J, Halett $M$, eds. Therapy with botulinum toxin. 1st ed. New York: Marcel Dekker, 1994:267-78.

27 Zuber M, Sebald M, Bathien MD, de Recondo J, Rondot J. Botulinum antibodies in dystonic patients treated with Botulinum antibodies in dystonic patients treated
type A botulinum toxin. Neurology 1993;43:1715-8.

28 Green P, Fahn S, Diamond B. Development of resistance to botulinum toxin type A in patients with torticolis. Mov Disord 1994;9:213-7.

29 Thilmann AF, Fellows SJ, Garms E. The mechanism of spastic muscle hypertonus. Brain 1991;114:233-44. 